\title{
Anti-Candida Activities and GC Mass Analysis of Seeds Hydroalcohlic Extract of Rumex obtusifolius
}

\author{
Hossein Nazari, ${ }^{1}$ Neda Bakhshandeh, ${ }^{1}$ Mahbubeh Gholami, ${ }^{1}$ Jamshid Mehrzad, ${ }^{3}$ and Farahnaz \\ Bineshian ${ }^{2, *}$ \\ ${ }^{1}$ Department of Biochemistry, Faculty of Medicine, Seman University of Medical Sciences, Semnan, Iran \\ ${ }^{2}$ Department of Mycology, Faculty of Medicine, Semnan University of Medical Sciences, Semnan, Iran \\ ${ }^{3}$ Department of Biochemistry, Faculty of Basic and Research Science, Azad University, Neyshabur Branch, Neyshabur, Iran \\ "Corresponding author: Farahnaz Bineshian, Department of Mycology, Faculty of Medicine, Semnan University of Medical Sciences, Semnan, Iran. Tel: +98-233354170-3, Fax: \\ +98-23-3354161, E-mail: fzbineshian@yahoo.com
}

Received 2016 November 12; Revised 2017 April 12; Accepted 2017 May 02.

\begin{abstract}
Background: Nowadays, the use of herbal medicines in the prevention and treatment of diseases has been increased in the world, especially in Iran. Developing chemical drugs resistance in some Candida species and their side effects, conducting research to find new resources, especially medicinal plants, are of prime importance.

Objectives: The present study aimed at evaluating anti-Candida activities and antioxidant function of hydroalcohlic extract of seeds of Rumex obtusifolius and analyzing GC mass for the determined material, which included especial formulated extract.

Methods: The Rumex obtusifolius seeds were extracted using Ethyl acetate: methanol: distilled water (6:3:1) by Soxhelet system. The antifungal activity as well as total free phenolics and flavonoids content were examined. The extract was carried out against 40 isolated Candida species such as Candida albicans and C. glabrata through well diffusion method. In addition, hydroalcoholic extraction of R. obtusifolius was evaluated for its antioxidant capacities using 1-diphenyl-2-picrylhydrazyl radical scavenging. The components of the extract were analyzed via Gas chromatography-Mass spectrometry (GC-Mass) instrument.

Results: The minimum inhibitory concentration (MIC) values were $100-150 \mu \mathrm{g} / \mu \mathrm{L}$ for C. albicans $150 \mu \mathrm{g} / \mu \mathrm{L}$ for C. glabrata. The hydroalcoholic extract can strongly scavenge DPPH radical, and its antioxidant capacities may be correlated with the total free phenolics and total flavonoids. This study revealed the highest antioxidant capacity in the seeds of R. obtusifolius compared to the control groups.

Conclusions: The extract contained a high amount of phenolic compounds, and its antioxidant activity was significant. The seed of R. obtusifolius has strong anticandidial and antioxidant activities, which may be due to the presence of high levels of phenolic compounds, particularly pyrogallol.
\end{abstract}

Keywords: GC-Mass, Hydro Alcoholic Extract, Rumex obtusifolius, Candida

\section{Background}

The Rumex species, belonging to Polygonaceae family, includes approximately 200 species, which are distributed all over the world. Rumex obtusifolius is a perennial plant widely distributed in North America, Europe, and Iran. It is native to these regions and is commonly known as "Torshak" in Iran and its local name is "toopa" in Mahdishahr (Sangsar), Semnan, Iran. The leaves of this plant are used in foods and soups and they are also used as a raw vegetable. The seeds are used as flour (1). Leaves, the root, and seeds, which have medicinal properties, are used as an herbal medicine.

Rumex obtusifolius is used in the treatment of different diseases. The seeds of $R$. obtusifolius are used to treat coughs, colds, bronchitis, cancer, burns, and wounds. It was applied for the treatment of different types of tumors such as epidermal carcinoma, melanoma, and ovary carcinoma (2). Moreover, R. obtusifolius is used by Indian tribes to treat different diseases such as constipation, diarrhea, dysentery, jaundice, skin problems, stomachache, and they also use it as a contraceptive $(2,3)$. Rumex species are known to be rich in anthraquinones, with R. obtusifolius containing emodin, chrysophanol, and physcionin (2).
Prolonged and multiple antibiotic treatment, prolonged hospital stay, corticosteroid drugs, severe burns, surgery, cancer, AIDS, transplants patients, chemotherapy, and radiation increase the risk of candidiasis, caused by Candida spp particularly C. albicans. Nowadays, the use of herbal medicines in the prevention and treatment of illness has been increased in the world, especially in Iran.

\section{Objectives}

The present study aimed at evaluating the antioxidant and anti-Candida activities of $R$. obtusifolius seeds of hydroalcohlic extract and analyzing the components of this hydroalcoholic extract by Gas chromatography-Mass spectrometry (GC-Mass) instrument.

\section{Methods}

\subsection{Materials}

Candida albicans (ATCC10231), Candida strains, Dimethyl Sulphoxide (DMSO, Merk, Germany), Sabouraud dextrose broth (SDB, Merk, Germany), Sabouraud dextrose agar (SDA, Merk, Germany), L-ascorbic acid, 2, 2-Diphenyl-1-picryl hydrazyl (DPPH), Gallic acid, Quercetin, 
Butylated Hydroxy Toluene (BHT), Folin-Ciocalteu reagent, and trichloracetic acid (TCA) were prepared from Sigma-Aldrich. Also, reagents and chemicals had analytical grades. Spectrophotometric measurements were performed using a Spectronic. Spectronic Spekol, 2000 spectrophotometer (Analytik jena, Germany).

\subsection{Plant Collection}

Rumex obtusifolius was collected from Jashloobar garden located in the Northwest of Semnan, Iran. Experienced botanists of the University of applied science and technology(UAST) education center in Semnan branch recognized the seed of the plant. A testifier sample of R. obtusifolius was kept in the medicinal plants research herbarium center at UAST. Seeds of the plants were dried in the shade for a week after washed with running tap water, then, crushed into small pieces, and finally powdered using an electric blender. Plant seeds powder was then stored in plastic bags for further use.

\subsection{Preparation of the Plant Extracts}

Plant extracts were obtained by the following procedures: Ethanolic extract was obtained by incubating $50 \mathrm{~g}$ of powdered seeds with $500 \mathrm{~mL}$ of Ethyl acetate: methanol: distilled water (6:3:1) overnight at room temperature (RT) before adjusting to $40^{\circ} \mathrm{C}$ for 8 hours in a Soxhlet system. The extracts were centrifuged (3000 rpm) for 15 minutes and the supernatants harvested and filtered using Whatman paper No. 1. Then, the solvents were evaporated by incubation RT, and the powder of the extract was then stored in glass bottle for experiment. The extraction yields were calculated as the percentage of the used powder.

\subsection{Candida Strain and Inoculum Preparation}

\subsubsection{Preparation Serial Dilution of Hydroalcoholic Extract}

Two grams of hydroalcoholic extract of R. obtusifolius was solved in $5 \mathrm{~mL}$ Dimethyl Sulphoxide (DMSO). The final concentration was $400 \mu \mathrm{g} / \mu \mathrm{L}$ (4) and dilution series were prepared using sterile distilled water from 400, 200, $150,100,50,25$, and $12 / 5 \mu \mathrm{g} / \mu \mathrm{L}$. In the current study, C. albicans (ATCC10231) was used as the reference strain. A total of 40 Candida isolates (34 C. albicans and 6 C. glabrata from women with vulvovaginal candidiasis) (5) were inoculated in Sabourated dextrose broth and were incubated for 24 hours at $35^{\circ} \mathrm{C}$. The suspension was equal a yeast concentration of $1 \times 10^{6} \mathrm{CFU} / \mathrm{mL}$ (0.5 Mac-Farland standard). The commercial antifungal drugs "fluconazole disc" (10 $\mu \mathrm{g} /$ disc Hi-Media, Mumbai, India) and DMSO were applied as positive control and solvent control, respectively.
3.4.2. Broth Microdilution Method for Determination of Minimum Inhibitory Concentration (MIC)

Anti-fungal effect well diffusion method was used, and $100 \mu$ L of yeast inoculums $\left(10^{6}\right.$ cells $\left./ \mathrm{mL}\right)$ was cultured onto Sabouraud dextrose agar. The, wells were holed by pipette pasture into the SDA medium and filled with $100 \mu \mathrm{L}$ of serial dilutions of plant extracts, and sterile DMSO was used as negative control. Cultures were incubated at $35^{\circ} \mathrm{C}$ for 24 hours. The zone of inhibition was measured to determine anti-Candida activity. Tests were repeated 2 times (4).

\subsection{Determination of Total Phenolic Content}

Phenolic compounds of the R. obtusifolius hydroalcoholic extract were estimated using the Folin-Ciocalteu method described previously $(6,7)$. Briefly, the reaction mixture included $800 \mu \mathrm{L}$ of freshly prepared diluted Folin Ciocalteu reagent, $200 \mu$ L of diluted R. obtusifolius seeds extracts, $2 \mathrm{~mL}$ of $7.5 \%$ sodium carbonate, and the final mixture reached $10 \mathrm{~mL}$ with deionized water. Optical density (OD) of blue color, which resulted from reaction, was measured at $765 \mathrm{~nm}$ by Spectronic Spekol, 2000 spectrophotometer (Analytik jena, Germany) after incubation for 2 hours in darkness at the ambient conditions to complete the reaction at RT. The standard curve of Gallic acid was done for quantification (8).

\subsection{Determination of the Total Flavonoid Contents}

In the present study, $1 \mathrm{~mL}$ of the extract in methanol and different dilution of standard solution of Quercetin brought to $5 \mathrm{~mL}$ by distilled water. Then, $0.3 \mathrm{~mL}$ of $5 \%$ sodium nitrite and $0.3 \mathrm{~mL}$ of $10 \%$ aluminum chloride were added along with 5 and 6 minutes incubation time, respectively. Finally, $2 \mathrm{~mL}$ of $1 \mathrm{M}$ sodium hydroxide was added, and the total volume was made up to $10 \mathrm{~mL}$ with distillated water. The OD of the mixture pink in color was measured at $510 \mathrm{~nm}$ against a freshly prepared reagent blank. Total flavonoid content of the extracts was expressed as $\mathrm{mg}$ quercetin equivalents $(\mathrm{QE})$ per gram of the sample $(\mathrm{mg} / \mathrm{g})$ (9-11).

Concentration values of the extracts were taken from the Quercetin standard curve by interpolating to the Xaxis. Total flavonoid contents were calculated using the following formula:
$\mathrm{TFC}=\mathrm{R} \times \mathrm{D} . \mathrm{F} \times \mathrm{V} / \mathrm{w}$
Where
$\mathrm{R}$ - Results taken from the standard curve
D.F - Dilution factor
$\mathrm{V}$ - Volume of stock Solution
$\mathrm{W}$ - Weight of plants used in the experiment 


\subsection{DPPH Radical Scavenging Activity}

Samples were dissolved in 95\% methanol at a concentration of $1 \mathrm{mg} / \mathrm{mL}$ and prepared a series of concentrations “2, 1, 0.5, 0.25, 0.125, $0.0625 \mu \mathrm{g} / \mathrm{mL}$ ” for antioxidant assays. DPPH radical scavenging activity was estimated according to Burits et al. (12), Cuendet et al. (13), and others (1416). In this assay, a $50 \mu \mathrm{L}$ of various dilutions of the R. obtusifolius hydroalcoholic extracts solution (Stock $1 \mathrm{mg} / \mathrm{mL}$ concentration) was added with $5 \mathrm{~mL}$ of $0.004 \%$ methanolic DPPH and incubated for 30 minutes at RT after it was shaken strongly. The scavenging effect on the DPPH radical was read at $517 \mathrm{~nm}$ by spectrophotometer. Ascorbic acid and Butylated Hydroxy Toluene (BHT) were used as positive control and DPPH solution without sample solution was used as a control. IC50 values are the concentration of the sample required to scavenge $50 \%$ of DPPH free radical, which was calculated from the plotted graph of radical scavenging activity across the concentration of extracts.

The radical scavenging activity was expressed as the radical scavenging percentage using the following equation:

\% percentage DPPH radical scavenging: $I \%=\left(1-A_{s} / A_{c}\right)$ $\times 100$

Where $A_{c}=$ absorbance of control and $A_{s}=$ absorbance of sample solution

\subsection{Gas Chromatography-Mass Spectrometry Analysis}

The extract was analyzed using the Gas chromatography-Mass spectrometry (GC-MS, Agilent), equipped with a determined capillary column "DB-35 ms, $30 \mathrm{~m} \times 250 \mu \mathrm{m} \times 0.15 \mu \mathrm{m}$ ". A constant flow rate of Helium gas (99.99\%) as a carrier gas ( $1 \mathrm{~mL} / \mathrm{min})$ was used for GC-MS detection. Injector and mass transfer line temperature were set at $200^{\circ} \mathrm{C}$ and $240^{\circ} \mathrm{C}$, respectively. The oven temperature was ordered from $60^{\circ} \mathrm{C}$ to $280^{\circ} \mathrm{C}$ at $10^{\circ} \mathrm{C} / \mathrm{min} .1 \mu \mathrm{L}$ of diluted samples was injected, with split ratio of $1: 10$, with mass scan of 50 - 600 amu.

Total running time of GC-MS is 50 minutes. The extract constituent percentage was expressed as percentage with peak area normalization. The identity of the ingredients in the extract was specified by comparing their retention times and mass spectra fragmentation patterns with those replete on the computer library and by the results of the published articles. Willey library sources were used to match the identified components from the plant material.

\subsection{Statistical Analysis}

Statistical analysis was conducted by analysis of variance (ANOVA) at confidence level of 95\% using SPSS Version 16 software. Linear regression to correlate the antioxidant activity of the total phenolic and total flavonoid was performed using Excel 2003. P values less than 0.05 were considered significant for an anti-Candida activity.

\section{Results}

Rumex obtusifolius extraction of seeds was found to have the most anti-oxidant effect, whose total antioxidant activity and DPPH scavenging activity was determined using spectrophotometry.

\subsection{Extraction Yield, Total Polyphenolics, and Flavonoid Con- tents}

The phenolics and flavonoids contents as well as an antiradical activity vary depending on the extraction methods, genetic factors, and climatic/growing conditions. However, we preferred to use a different and more effective solvent system. As the results of one study (17) revealed that the ethyl acetate: methanol: distilled water (60:30:10) system is a well-known system to extract antioxidant compounds; the percent of yield of Rumex obtusifolius seeds hydroalcoholic extract was 5.3 gram.

\subsection{Anti-Candida}

The anti-Candida activity of hydroalcohlic extract of $R$. obtusifolius against C. albicans, C.glabrata is presented in Table 1. Hydroalcohlic extract of $R$. obtusifolius has shown anti-Candida activities against $C$. albicans $(\mathrm{n}=34)$ and $C$. glabrata $(\mathrm{n}=6)$. The highest inhibition zone was observed against $C$. albicans, with a range of $18 \pm 2.0 \mathrm{~mm}$ and a minimum inhibition zone of $15 \pm 2.0 \mathrm{~mm}$ and $100-150 \mu \mathrm{g} / \mu \mathrm{L}$ MIC values.

\subsection{DPPH Radical Scavenging Activity}

The antiradical activity of the hydroalcoholic extract, prepared from $R$. obtusifolius aerial organ and collected from Semnan in Iran, was examined. The extract showed high antioxidant activities in the 3 tested assays: DPPH method: This assay is known as a primary test since quenching odd electron of DPPH by the extract, which is associated with decreased absorption at $517 \mathrm{~nm}$. R. obtusifolius seeds extract showed a high level antiradical activity in scavenging DPPH radical (comparable to BHT as a standard), with a maximum inhibition of about 18.10 at a concentration of $1000 \mu \mathrm{g} / \mathrm{mL}$ (Table 2 upper panel). 
Table 1. Anti-Candida Activity of Hydroalcohlic Extract of Rumex Obtusifolius

\begin{tabular}{|c|c|c|c|c|}
\hline Variables & $\mathbf{4 0 0}, \mu \mathrm{g} / \mu \mathbf{L}$ & $150, \mu \mathbf{g} / \mu \mathbf{L}$ & $\mathbf{1 0 0}, \mu \mathbf{g} / \mu \mathbf{L}$ & Fluconazole \\
\hline Candida albicans & 18 & 16 & 15 & 20 \\
\hline Candida glabrata & 15 & 13 & 12 & 19 \\
\hline
\end{tabular}

Table 2. Effect of the Test Compounds in the DPPH Assay (Upper Panel) and Antioxidant Constituents of Rumex obtusifolius Hydroalcoholic Seed Extract (Lower Panel)

\begin{tabular}{|c|c|c|}
\hline \multirow{2}{*}{$\begin{array}{l}\text { Effect of the Test Compounds in the DPPH Assay } \\
\text { Test compound }\end{array}$} & \multicolumn{2}{|c|}{ Value } \\
\hline & $\mathrm{IC}_{50} \mathrm{a}$ & inhibition, \% \\
\hline Rumex obtusifolius & 23.63 & 8.87 \\
\hline Butylhydroxytoluene & 15.02 & 18.10 \\
\hline \multicolumn{3}{|l|}{ Antioxidant constituents of Rumex obtusifolius } \\
\hline Extract & Total phenolics $(\mathrm{GAE})^{\mathrm{a}}, \mathrm{mg} / \mathrm{g}$ & Total flavonoids $(\mathrm{QU})^{\mathrm{b}}, \mathrm{mg} / \mathrm{g}$ \\
\hline Rumex obtusifolius & $333.87 \pm 7.22^{\mathrm{c}}$ & $410 \pm 25.46$ \\
\hline
\end{tabular}

${ }^{\text {a }}$ Expressed as Gallic acid equivalent (GAE).

${ }^{\mathrm{b}}$ Expressed as Quercetin equivalent (QU).

${ }^{\mathrm{C}} \mathrm{A}$ Values represent averages \pm standard deviations for triplicate experiments.

\subsection{Bioactive Content}

\subsubsection{Total Free Phenolics}

Phenolic compounds are most common secondary metabolites found in plants including flavonoids, tannins, and phenolic acids. The total phenolic content (TPC) of the R. obtusifolius was determined spectrophotometrically according to the method of Folin-Ciocalteu, and the results were expressed as Gallic acid equivalent. The standard curve equation used was $\mathrm{y}$ (absorbance $)=0.038 \times(\mu \mathrm{g}$ Gallic acid) - $0.0132, \mathrm{R}^{2}=0.9859$ (Figure 1). The OD value was inserted in the above equation, and the total amount of phenolic compound was calculated. As displayed in Table 2, lower panel, the total phenolic content of the $R . o b$ tusifolius seeds was $97.49 \pm 5.36$.

\subsubsection{Determination of Total Flavonoid Content}

Flavonoids are polyphenolic molecules that protect the plants against stress effect. The flavonoids are divided into 6 major subtypes, which include chalcones, flavones, isoflavonoids, flavanones, anthoxanthins, and anthocyanins. The total flavonoids content of the R. obtusifolius was determined spectrophotometrically according to the method of Folin-Ciocalteu, and the results were expressed as Quercetin equivalent. The standard curve equation used was as follows: $\mathrm{y}$ (absorbance) $=0.0005 \times(\mu \mathrm{g}$ Quercetin) - 0.014, $\mathrm{R}^{2}=0.9615$ (Figure 2). The OD value was inserted in the above equation, and the total amount of flavonoid compound was calculated. The overall mean \pm SD of the total flavonoids was $332 \pm 5.66 \mathrm{mg} / \mathrm{g}$ (Table 2, lower panel).

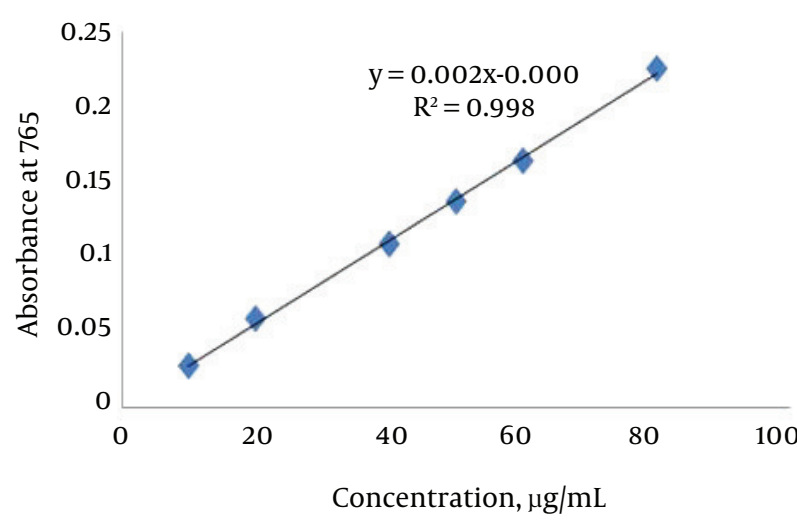

Figure 1. Calibration Curve of Standard Gallic Acid to Determine Total Phenol Content

\section{5. Gas Chromatography-Mass Spectrometry Analysis}

The GC-MS analysis of the extracts showed the presence of phytocomponents; in total, 9 constituents were identified in the R. obtusifolius seed extract (Table 3). In this research, 9 chemical constituents were identified from the seeds of the hydroalcohlic extract of R. obtusifolius. The major chemical constituents are 1, 2, 3-Benzenetriol (Pyrogallol) $62.821 \%$, Octadecenoic acid (oleic acid) $11.976 \%$, Hexadecanoic acid (Palmitic acid) 10.095\%, and Linoleic acid 8.5\%. Pyrogallol is found in many plants naturally. Pyrogallol was the predominant phenolic compound in the seed extract. 
Table 3. Chemical Analyses Constituents of Hydro Alcoholic Extract of Seed R. Obtusifolius which are based on GC Mass Peak Areas. Source of Confirm Compound Nature of Seeds Extract Are Dr. Duke's Phytochemical and Ethnobotanical Databases (Online Database) and. S. Gopalakrishnan Research Article, Entitled: GC-MS Analysis of Some Bioactive Constituents of Mussaenda Frondosa Linn Which Published in International Journal of Pharma and Bio Sciences, 2011

\begin{tabular}{|c|c|c|c|c|c|}
\hline No. & Component & Peak area, \% & Retention Time (RT) & Compound Nature & Activity \\
\hline $\mathbf{1}$ & 4H-Pyran-4-one & 0.843 & 18.577 & Flavonoid fraction & Antimicrobial and ,Anti inflammatory \\
\hline 2 & $\begin{array}{l}\text { Diimidazole, 5-Ethoxy } \\
\text {-4-phenyl-2-isopropylpheno }\end{array}$ & 0.783 & 22.347 & - & - \\
\hline 3 & Phenol, 2,6- Pyrogallol 1,3- methoxyphenol & 1.924 & 23.345 & Phenolic compound & $\begin{array}{l}\text { Antimicrobial, Antioxidant, } \\
\text { Antiinflammatory, Analgesic }\end{array}$ \\
\hline 4 & 1,2,3-Benzenetriol & 62.800 & 31.055 & Pyrogallol & $\begin{array}{l}\text { Antidermatitic, Antioxidant, Antiseptic, } \\
\text { Fungicide, Insecticide, Candidicide }\end{array}$ \\
\hline 5 & Hexadecanoic acid & 10.095 & 35.811 & Palmitic acid ester & $\begin{array}{l}\text { Antioxidant, Hypocholesterolemic, } \\
\text { Nematicide, Pesticide, Lubricant, } \\
\text { Antiandrogenic, Flavor, Hemolytic 5-Alpha } \\
\text { reductase inhibitor }\end{array}$ \\
\hline 6 & Octadecenoic acid & 11.976 & 39.246 & Oleic acid & $\begin{array}{l}\text { Antiinflammatory, Antiandrogenic, } \\
\text { Cancer preventive, Dermatitigenic, } \\
\text { Hypocholesterolemic, 5-Alpha, reductase } \\
\text { inhibitor, Anemiagenic ,Insectifuge, Flavor }\end{array}$ \\
\hline 7 & Linoleic acid & 8.5 & 39.321 & Linoleic acid & $\begin{array}{l}\text { Antiinflammatory, Hypocholesterolemic, } \\
\text { Cancer, preventive Hepatoprotective, } \\
\text { Nematicide, Insectifuge, Antihistaminic, } \\
\text { Antieczemic, Antiacne, 5-Alpha reductase } \\
\text { inhibitor, Antiandrogenic, Antiarthritic, } \\
\text { Anticoronary, Insectifuge }\end{array}$ \\
\hline 8 & Methyl dihydromalvalate, Eicosanoic acid & 2.937 & 39.663 & - & - \\
\hline 9 & Pentadecenoic acid & 0.123 & 42.564 & - & - \\
\hline Total & & 99.98 & & & \\
\hline
\end{tabular}

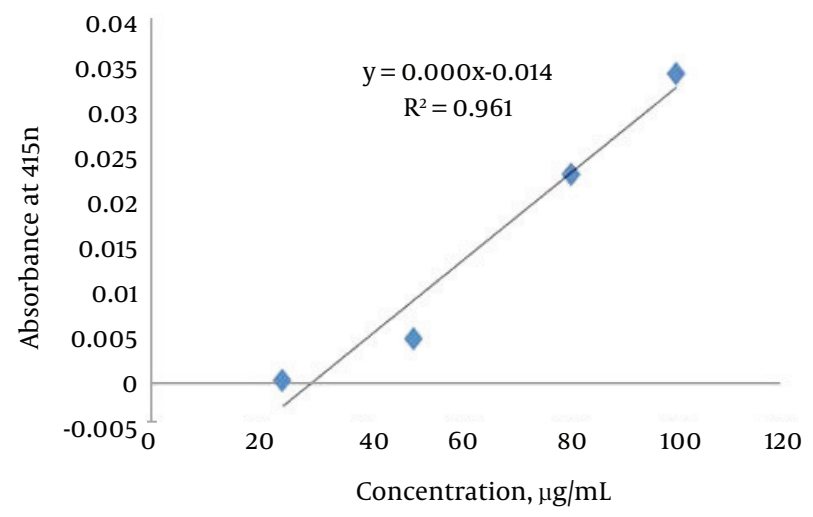

Figure 2. Calibration Curve of Standard Quercetin to Determine the Total Flavonoid Content in R. Obtusifolius

\section{Discussion}

In the recent decades, the increase in using immunocompromised drugs and antibiotics for long periods has led to increase of infectious diseases and candidiasis. However, an increase in the use of chemical antifungal drugs and an increase in the prevalence of drug resistant C. al- bicans have been observed. Researchers have paid attention to the use of pharmaceutical compounds from natural plant sources, and traditional medicine has proven the benefits of herbal medicines. Antioxidants play an important role in preventing human diseases (6). Natural resources compounds with antioxidants activity may function as free radical scavengers and reduce agents, protecting the body from degenerative diseases (18). The antioxidant activity of seed extract was examined by its ability to scavenge the stable DPPH free radicals. The results showed that the seed extract of $R$. obtusifolius has the highest inhibition zone, which was observed against $C$. albicans with a range of $18 \pm 2.0 \mathrm{~mm}$, and a minimum inhibition zone of $15 \pm 2.0 \mathrm{~mm}$, and $100-150 \mu \mathrm{g} / \mu \mathrm{L}$ MIC values.

On the other hand, the seed extract will be able to reduce free radicals significantly. It is related to the presence of high amounts of flavonoids, and phenolic acids in seeds of $R$. obtusifolius. These findings are in agreement with other studies $(18,19)$. Many studies have shown that the pyrogallol displays a broad spectrum of pharmacological and promotes health effects in animal models of disease. Pyrogallol has been reported to possess the ability to scavenge free radicals, antioxidant action, and inhibit the formation of carcinogenic metabolites (20-24). Pyrogal- 
lol was also evaluated as a potential inhibitor for acethylcholinesterse enzyme (25).

Baruah et al. (26) reported that the potency of pyrogallol to induce protective immunity makes it a probable natural protective agent that might avoid different infections and this compound is as potential antimicrobial agent. Kang et al. (27) reported that the antioxidant activities of pyrogallol were higher than those of the commercial antioxidant and ascorbic acid, moreover, they found that pyrogallol effectively inhibited DNA damage induced by $\mathrm{H}_{2} \mathrm{O}_{2}(21,28)$. Our results revealed that the seed of $R$. obtusifolius has strong antioxidant and anticandidial activities, which may be due to the presence of high levels of phenolic compounds, particularly pyrogallol. These findings are in agreement with other studies $(21,22)$. In addition, Sadeghi Nejad et al. (4) reported the anti-candida activity of Heracleum persicum hydroalcoholic extract. Mahdavi Omran et al. (29) reported the anti-candida activity essential oils of some medicinal plant such as thyme, pennyroyal, and Lemon in Iran.

In conclusion, the natural antioxidative compound "pyrogallol" can be used in the natural food industry as well as a part of some medicinal plant drugs such as antioxidative and anticancer drugs because of their efficacy, availability, low cost, and low toxicity. The phenolic and flavonoids compounds with great potential of antioxidant and antifungal are available. However, further research needs to be done to introduce natural medicine to treat different diseases and introduce it as a therapeutic and natural agent, with antioxidant and fungicides compounds.

\section{References}

1. Pareek A, Kumar A. Rumex crispus L.-A plant of traditional value. Drug Discovery. 2014;9(20):20-3.

2. Vasas A, Orban-Gyapai O, Hohmann J. The Genus Rumex: Review of traditional uses, phytochemistry and pharmacology. J Ethnopharmacol. 2015;175:198-228. doi: 10.1016/j.jep.2015.09.001. [PubMed: 26384001].

3. Harshaw D, Nahar L, Vadla B, Saif-E-Naser G, Sarker S. Bioactivity of Rumex obtusifolius (Polygonaceae). Arch Biol Sci. 2010;62(2):387-92. doi: $10.2298 / a b s 1002387 \mathrm{~h}$.

4. Sadeghi Nejad B, Rajabi M, Zarei Mamoudabadi A, Zarrin M. In Vitro Anti-Candida Activity of the Hydroalcoholic Extracts of Heracleum persicum Fruit Against Phatogenic Candida Species. Jundishapur J Microbiol. 2014;7(1):e8703. doi: 10.5812/jjm.8703. [PubMed: 25147655].

5. Bineshian F, Yadegari MH, Sharifi Z, Akbari Eidgahi M, Nasr R. Identification of Candida Species Using MP65 Gene and Evaluation of the Candida albicans MP65 Gene Expression in BALB/C Mice.Jundishapur J Microbiol. 2015;8(5):e18984. doi: 10.5812/jjm.8(5)2015.18984. [PubMed: 26060567].

6. Zheng W, Wang SY. Antioxidant activity and phenolic compounds in selected herbs. I Agric Food Chem. 2001;49(11):5165-70. doi: 10.1021/jf010697n. [PubMed: 11714298].

7. Liu M, Li XQ, Weber C, Lee CY, Brown J, Liu RH. Antioxidant and antiproliferative activities of raspberries. J Agric Food Chem. 2002;50(10):2926-30. doi: 10.1021/jf0111209. [PubMed: 11982421].
8. Wolfe K, Wu X, Liu RH. Antioxidant activity of apple peels. J Agric Food Chem. 2003;51(3):609-14. doi:10.1021/jf020782a. [PubMed: 12537430].

9. Tesoriere L, Butera D, Gentile C, Livrea MA. Bioactive components of caper (Capparis spinosa L.) from Sicily and antioxidant effects in a red meat simulated gastric digestion. J Agric Food Chem. 2007;55(21):8465-71. doi: 10.1021/jf0714113. [PubMed: 17887802].

10. Tepe B, Sokmen M, Akpulat HA, Sokmen A. Screening of the antioxidant potentials of six Salvia species from Turkey. Food Chem. 2006;95(2):200-4. doi: 10.1016/j.foodchem.2004.12.031.

11. Tlili N, Nasri N, Khaldi A, Triki S, MunnÉ-Bosch S. Phenolic compounds, tocopherols, carotenoids and vitamin c of commercial caper. J Food Biochem. 2011;35(2):472-83. doi:10.1111/j.1745-4514.2010.00396.x.

12. Burits M, Bucar F. Antioxidant activity of Nigella sativa essential oil. Phytother Res. 2000;14(5):323-8. doi: 10.1002/10991573(200008)14:5<323::AID-PTR621>3.0.CO;2-Q. [PubMed: 10925395].

13. Cuendet M, Hostettmann K, Potterat O, Dyatmiko W. Iridoid glucosides with free radical scavenging properties from fagraea blumei. Helv Chim Acta. 1997;80(4):1144-52. doi: 10.1002/hlca.19970800411.

14. Kirby AJ, Schmidt RJ. The antioxidant activity of Chinese herbs for eczema and of placebo herbs-I. J Ethnopharmacol. 1997;56(2):103-8. doi:10.1016/S0378-8741(97)01510-9. [PubMed: 9174970].

15. Hinneburg I, Damien Dorman HJ, Hiltunen R. Antioxidant activities of extracts from selected culinary herbs and spices. Food Chem. 2006;97(1):122-9. doi: 10.1016/j.foodchem.2005.03.028.

16. Tomaino A, Cimino F, Zimbalatti V, Venuti V, Sulfaro V, De Pasquale $A$, et al. Influence of heating on antioxidant activity and the chemical composition of some spice essential oils. Food Chemistry. 2005;89(4):549-54. doi: 10.1016/j.foodchem.2004.03.011.

17. Rezzan A, Ozan EE, Huseyin S, Oktay Y, Nimet B. Phenolic components, antioxidant activity, and mineral analysis of Capparis spinosa L. Afr J Biotechnol. 2013;12(47):6643-9. doi:10.5897/ajb2013.13241.

18. Yildirim A, Mavi A, Kara AA. Determination of antioxidant and antimicrobial activities of Rumex crispus L. extracts. J Agric Food Chem. 2001;49(8):4083-9. doi: 10.1021/jf0103572. [PubMed: 11513714].

19. Suh HJ, Lee KS, Kim SR, Shin MH, Park S, Park S. Determination of singlet oxygen quenching and protection of biological systems by various extracts from seed of Rumex crispus L.J Photochem Photobiol B. 2011;102(2):102-7. doi: 10.1016/j.jphotobiol.2010.09.008. [PubMed: 21185197].

20. Park WH, Han YW, Kim SH, Kim SZ. A superoxide anion generator, pyrogallol induces apoptosis in As4.1 cells through the depletion of intracellular GSH content. Mutat Res. 2007;619(1-2):81-92. doi: 10.1016/j.mrfmmm.2007.02.004. [PubMed:17382355].

21. Mitsuhashi S, Saito A, Nakajima N, Shima H, Ubukata M. Pyrogallol structure in polyphenols is involved in apoptosis-induction on HEK293T and K562 cells. Molecules. 2008;13(12):2998-3006. doi: 10.3390/molecules13122998. [PubMed: 19052524].

22. Elzaawely AA, Xuan TD, Tawata S. Antioxidant and antibacterial activities of Rumex japonicus HOUTT. Aerial parts. Biol Pharm Bull. 2005;28(12):2225-30. [PubMed: 16327154].

23. Defoirdt T, Pande GS, Baruah K, Bossier P. The apparent quorumsensing inhibitory activity of pyrogallol is a side effect of peroxide production. Antimicrob Agents Chemother. 2013;57(6):2870-3. doi: 10.1128/AAC.00401-13. [PubMed: 23545532].

24. Chen $\mathrm{CH}$, Liu TZ, Chen $\mathrm{CH}$, Wong $\mathrm{CH}$, Chen $\mathrm{CH}$, Lu FJ, et al. The efficacy of protective effects of tannic acid, gallic acid, ellagic acid, and propyl gallate against hydrogen peroxide-induced oxidative stress and DNA damages in IMR-90 cells. Mol Nutr Food Res. 2007;51(8):962-8. doi: 10.1002/mnfr.200600230. [PubMed: 17628875].

25. Ozturk Sarikaya SB. Acethylcholinesterase inhibitory potential and antioxidant properties of pyrogallol. J Enzyme Inhib Med Chem. 2015;30(5):761-6. doi: 10.3109/14756366.2014.965700. [PubMed: 25297710].

26. Baruah K, Duy Phong HP, Norouzitallab P, Defoirdt T, Bossier P. The gnotobiotic brine shrimp (Artemia franciscana) model system reveals that the phenolic compound pyrogallol protects against infec- 
tion through its prooxidant activity. Free Radic Biol Med. 2015;89:593601. doi: 10.1016/j.freeradbiomed.2015.10.397. [PubMed: 26459033].

27. Kang SM, Lee SH, Heo SJ, Kim KN, Jeon YJ. Evaluation of antioxidant properties of a new compound, pyrogallol-phloroglucinol-6,6'bieckol isolated from brown algae, Ecklonia cava. Nutr Res Pract. 2011;5(6):495-502. doi: 10.4162/nrp.2011.5.6.495. [PubMed: 22259673].

28. Mendes V, Vilaca R, de Freitas V, Ferreira PM, Mateus N, Costa V.
Effect of myricetin, pyrogallol, and phloroglucinol on yeast resistance to oxidative stress. Oxid Med Cell Longev. 2015;2015:782504. doi: 10.1155/2015/782504. [PubMed: 26000072].

29. Mahdavi Omran S, Esmailzadeh S. Comparison of anti-Candida activity of thyme, pennyroyal, and lemon essential oils versus antifungal drugs against Candida species. Jundishapur J Microbiol. 2009;2(2):5360. 